\title{
Current State of the Art in Ventricle Tissue Engineering
}

\author{
Ravi K. Birla* \\ BIOLIFE4D, Houston, TX, United States
}

The field of ventricle tissue engineering is focused on bioengineering highly functioning left ventricles that can be used as model systems for basic cardiology research and for cardiotoxicity testing. In this article, we review the current state of the art in the field of ventricle tissue engineering and discuss different strategies that have been used to bioengineer ventricles. Based on this body of literature, there are now common themes in the field that provide guidance for future directives, also presented in this article.

Keywords: bioengineering, bioreactors, patches, stem cells, electrical stimulation

\section{OVERVIEW OF CARDIAC TISSUE ENGINEERING}

\section{OPEN ACCESS}

Edited by:

Vincenzo Lionetti,

Sant'Anna School of Advanced

Studies, Italy

Reviewed by:

David Sedmera,

Charles University, Czechia

Sanjiv Dhingra,

University of Manitoba, Canada

${ }^{*}$ Correspondence:

Ravi K. Birla

rkbirla2@gmail.com

Specialty section:

This article was submitted to

Cardiovascular Biologics and

Regenerative Medicine,

a section of the journal

Frontiers in Cardiovascular Medicine

Received: 05 August 2020

Accepted: 12 October 2020

Published: 03 November 2020

Citation:

Birla RK (2020) Current State of the

Art in Ventricle Tissue Engineering.

Front. Cardiovasc. Med. 7:591581.

doi: 10.3389/fcvm.2020.591581
According to the American Heart Association, Heart Disease and Stroke Statistics update 2020 (1), the most recent year available at the time of this publication, cardiovascular disorders accounted for 859,125 deaths in the US out of a total of 2,813,503 registered deaths for the year 2017 (1). Cardiovascular disorders come at a very high cost, estimated to be $\$ 1.1$ trillion by the year 2035 , with direct medical cost estimated to reach $\$ 748.7$ billion and indirect cost estimated to be $\$ 368$ billion (1). Given the severity of cardiovascular disorders in the USA, there is an urgent need to develop novel and innovative therapies to help these patients. Cardiac tissue engineering is one such example, a field in which scientists and researchers are working rigorously to develop innovative technologies to help patients with cardiovascular disorders in need of these lifesaving therapies $(2,3)$.

Research in the field of tissue engineering is focused on fabricating tissue and organs that can be used for clinical transplantation. One of the first publications describing engineering of functional tissue was in 1988, when it was shown that primary hepatocytes isolated from rodent were cultured in three-dimensional matrices fabricated using three different polymers, polyglactin, polyorthoester, and polyanhydride (4). The primary hepatocytes were shown to maintain viability, function, and engraftment within the three-dimensional matrices. This work was seminal as it was the first time that primary cells were cultured within three-dimensional matrices to form functional tissue, the basis of tissue engineering as a scientific discipline.

The field of cardiac tissue engineering includes heart muscle tissue (2, 3), aortic valves (5), vascular grafts $(6-8)$, vascular networks $(9,10)$ and Purkinje networks, left ventricles $(11)$, and whole hearts (12) (Figure 1). While heart muscle tissue engineering is now an established field (3), the same is not true for ventricle bioengineering, a niche field and the focus on this review article.

\section{PROCESS TO BIOENGINEER VENTRICLES}

There is a large body of literature describing methods to bioengineer cardiovascular tissue constructs (13-17), based on which a methodological process has now evolved (Figure 2). The first step in the process is cell sourcing, generating a large number of contractile cardiomyocytes (CMs). 


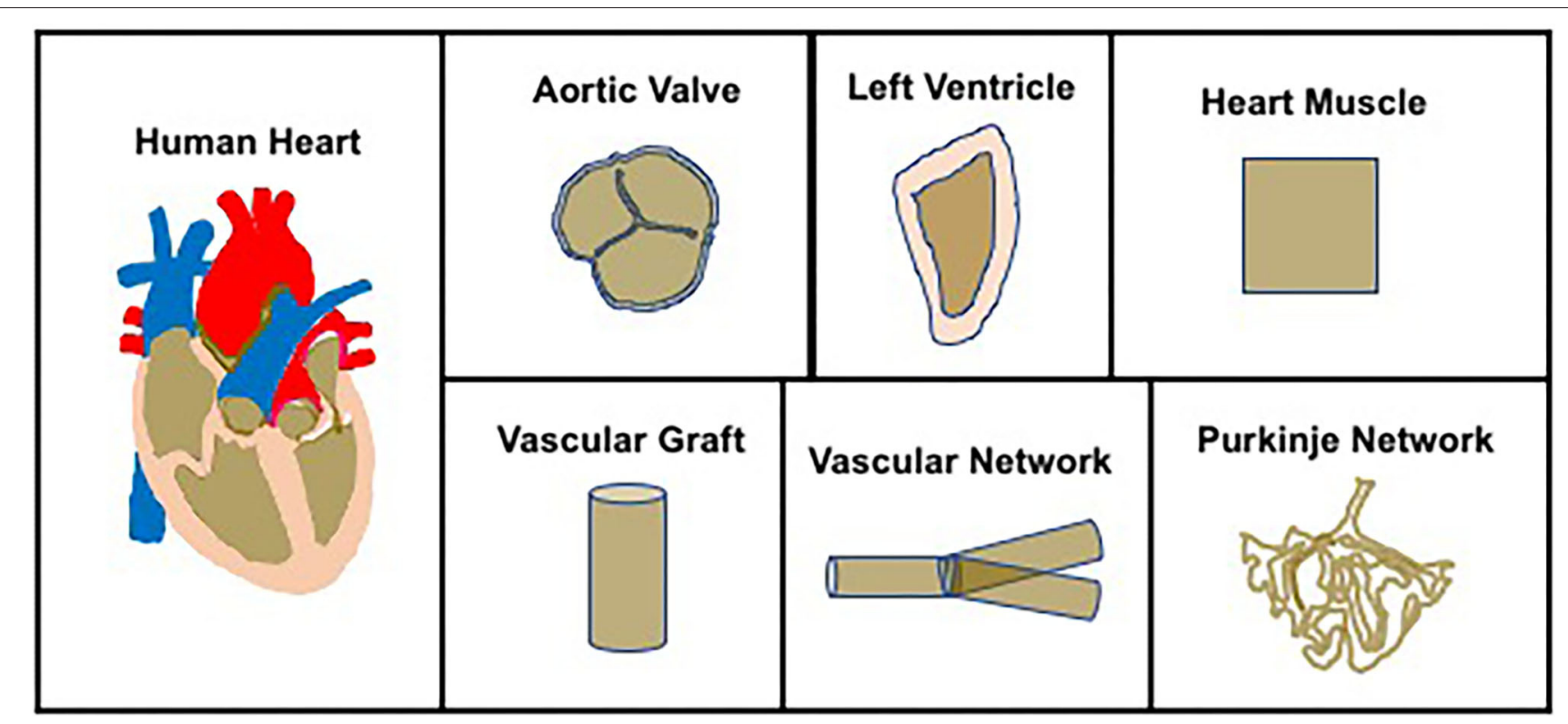

FIGURE 1 | Overview of cardiac tissue engineering - The field of cardiac tissue engineering is focused on bioengineering whole hearts or components of the heart, to include aortic valve, left ventricles, heart muscle, vascular grafts, vascular networks, and Purkinje networks.

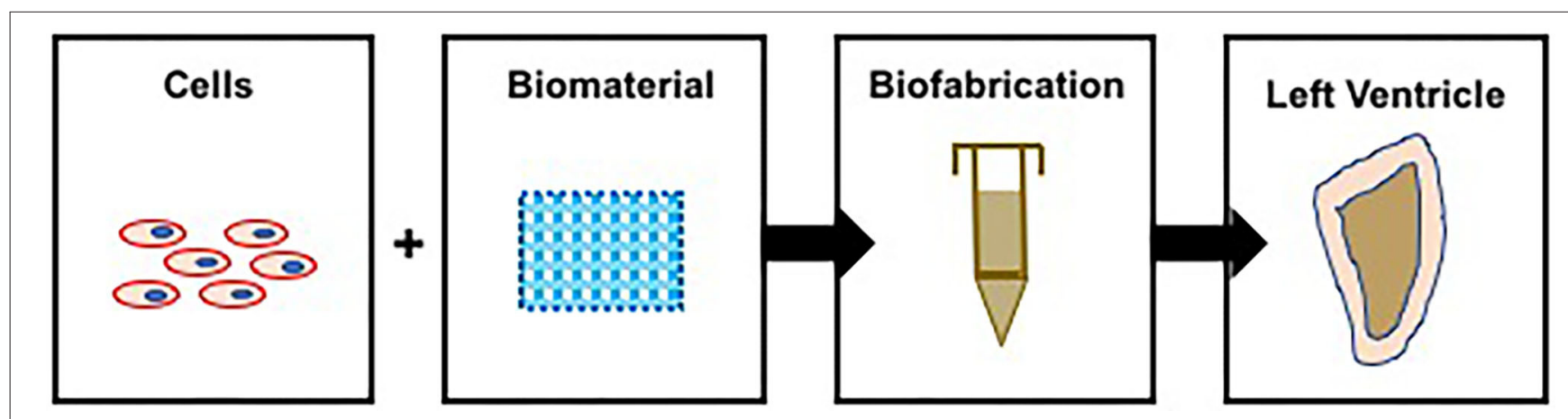

FIGURE 2 | Process to bioengineer ventricles - contractile CMs are coupled with biomatrices and used to bioprint functional ventricles. Note: in this illustration, bioprinting is used to illustrate the process to bioengineer ventricles.

Neonatal ventricular rat myocytes (NVRMs) are used for initial proof-of-concept studies and model development and validation efforts, while induced pluripotentent stem cell (iPSC)derived CMs are used for clinical studies. The second step involves biomaterial synthesis, which entails the development of novel biomaterials that can be used to simulate mammalian extracellular matrix (ECM). A large number of biomaterials have been used in the field, to include collagen type I, fibrin, gelatin, alginate, and chitosan, to name a few (18). The third step involves coupling contractile CMs with novel biomaterials to generate functional ventricles, in other words, develop novel fabrication methods to bioengineer functional ventricles. The fourth and final step is in vitro conditioning of bioengineered ventricles using bioreactors for coupled electromechanical stimulation.

\section{THE NEED FOR BIOENGINEERED VENTRICLES}

The notion to bioengineer cardiac patches is easy to understand as the potential applications to repair infarcted myocardium tissue are now well-established $(18,19)$. Similarly, the utility of vascular grafts, aortic and mitral valves, and whole hearts for potential therapeutic purposes is evident and well-described (19). However, the rationale to bioengineer ventricles is not as straightforward as there is no obvious therapeutic target for bioengineered ventricles. However, irrespective of the lack of a clear therapeutic target, there are many reasons to bioengineer ventricles. First and foremost, the holy grail of tissue engineering is to bioengineer a complete bioartificial and the experience gained in ventricle bioengineering is critical to accomplishing this 


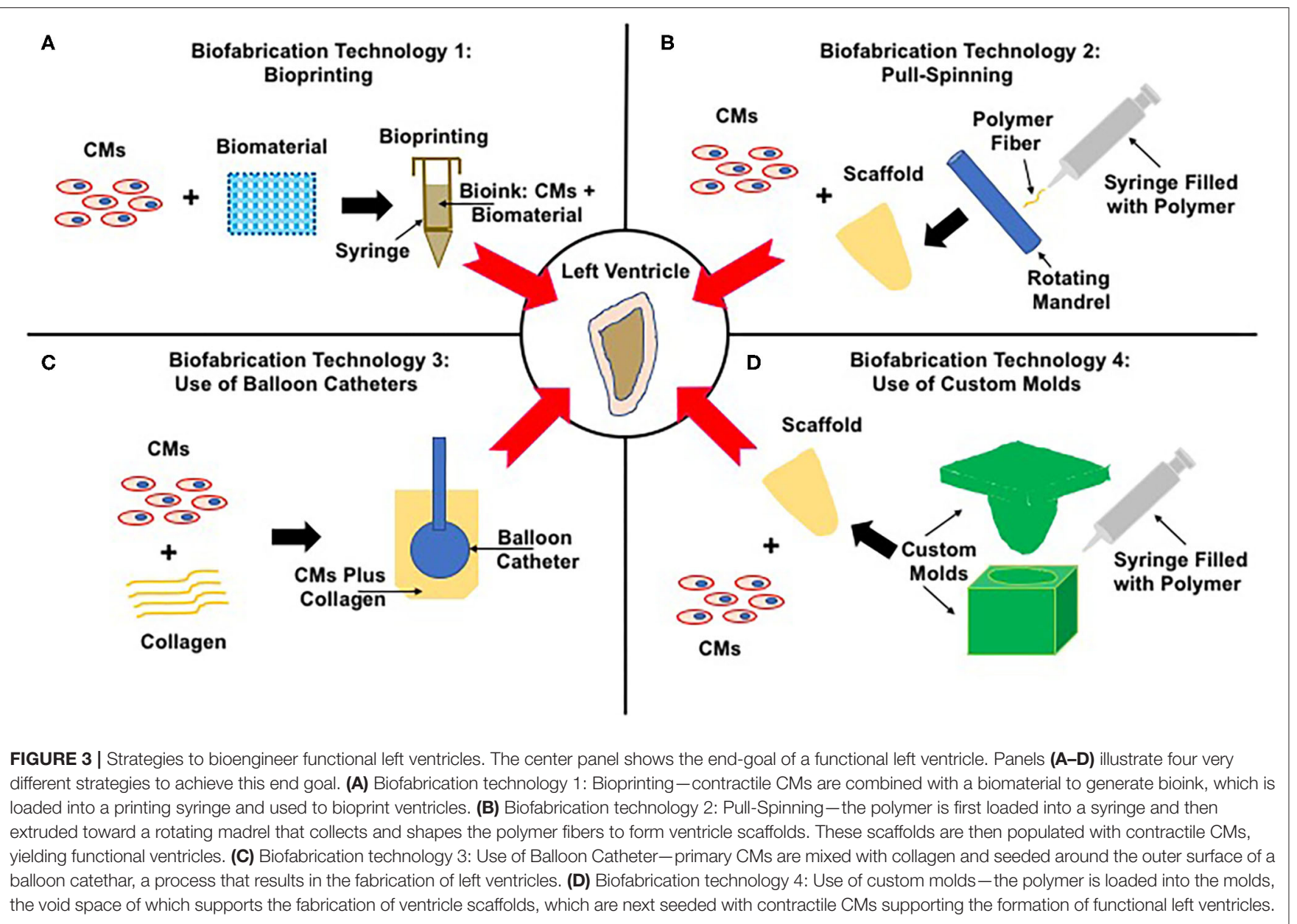

goal. Second, bioengineered ventricles provide valuable tools to study fluid dynamics in an isolated in vitro system and can also be used to understand the role of pressure and volume overload and other complex physiological phenomena, oftentimes difficult to study using existing models. Third, a complete left ventricle that contains a hollow chamber, contractile heart muscle, and mitral valves, including outflow and inflow tracts, can be used to investigate and understand the interrelationship between all these tissue components during heart function, something that would not be possible using any other in vitro or in vivo model systems. Fourth, bioengineered ventricles can be used to study cardiotoxicity effects of pharmacological agents, thereby reducing the animal cost.

\section{Strategies to Bioengineer Functional Ventricles}

There are several different established strategies in place to bioengineer ventricles, differing in the source of contractile CMs and biomaterial and biofabrication technology (Figure 3, Table 1). The major difference in these methods lies in the biofabrication technology, introduced here and discussed in detail in subsequent sections.
Biofabrication Technology 1: Bioprinting (Figure 3A, Table 1) - cells are combined with a biomaterial and loaded into a syringe, and a software program is used to guide the extrusion of the cell-biomaterial mixture (known as the bioink) to print a 3D structure, a ventricle in this case.

Biofabrication Technology 2: Pull-Spinning (Figure 3B, Table 1) - the biomaterial is ejected from a nozzle to a rotating collection device resulting in the formation of a ventricle scaffold, which is then populated with contractile CMs.

Biofabrication Technology 3: Use of Balloon Catheter (Figure 3C, Table 1)-contractile CMs coupled with a biomatrix and cast around the outer surface of a balloon catheter to generate hollow chambered ventricles.

Biofabrication Technology 4: Use of Custom Molds (Figure 3D, Table 1) -negative molds are first fabricated and then used to bioengineer ventricle scaffolds, which are then populated with contractile CMs.

\section{Biofabrication Technology 1: Bioprinting}

Bioprinting is a process by which cells are first combined with the biomaterial to form bioink, which is next loaded into a syringe, and using pneumatic pressure, the bioink is extruded from the syringe a single layer at a time. Multiple layers are 
TABLE 1 | Methods to bioengineer functional ventricles.

\begin{tabular}{|c|c|c|c|c|c|c|c|c|c|c|c|}
\hline Year & Cells & Matrix & $\begin{array}{l}\text { Fabrication } \\
\text { method }\end{array}$ & Bioreactors & Valve & $\begin{array}{l}\text { Pressure } \\
(\mathrm{mm} \mathrm{Hg})\end{array}$ & $\begin{array}{l}\text { Electrical } \\
\text { properties }\end{array}$ & $\begin{array}{l}\text { Calcium } \\
\text { transients }\end{array}$ & PV loops & Novelty & References \\
\hline 2018 & $\begin{array}{l}\text { iPSCs-CMs } \\
\text { and NVRMs }\end{array}$ & $\begin{array}{l}\text { PCL and } \\
\text { Gelatin }\end{array}$ & $\begin{array}{l}\text { Pull } \\
\text { spinning }\end{array}$ & $\begin{array}{l}\text { Yes, } \\
\text { mechanical } \\
\text { loading }\end{array}$ & YES & 0.05 & NO & YES & YES & $\begin{array}{l}\text { Use of pull } \\
\text { spinning }\end{array}$ & (3) \\
\hline 2018 & ESCs-CMs & $\begin{array}{l}\text { Collagen } \\
\text { type I }\end{array}$ & $\begin{array}{l}\text { Balloon } \\
\text { catheter }\end{array}$ & $\begin{array}{l}\text { Yes, electrical } \\
\text { stimulation }\end{array}$ & NO & 0.09 & YES & NO & YES & $\begin{array}{l}\text { Use of } \\
\text { catheters }\end{array}$ & (4) \\
\hline 2020 & iPS-CMs & $\begin{array}{l}\text { Collagen } \\
\text { type I }\end{array}$ & Bioprinting & NO & NO & $\begin{array}{l}\text { Not } \\
\text { reported }\end{array}$ & NO & YES & NO & $\begin{array}{l}\text { Use of FRESH } \\
\text { technology }\end{array}$ & (2) \\
\hline
\end{tabular}

iPSC, induced pluripotent stem cells; CMs, cardiomyocytes; ES, embryonic stem cells; NVRMs, neonatal ventricular rat myocytes.

extruded, often times 100 or more, each layer with a thickness of 100-500 microns, to form a complex 3D tissue and/or organ structure (19). Bioprinting is an established method and has been used extensively in cardiovascular tissue engineering (2025). The primary advantage of bioprinting is the ability to regulate the spatial organization of different cell types relative to each other and relative to the ECM. Since all mammalian tissue and organs are composed of multiple cell types within complex ECM, bioprinting allows recapitulation of mammalian tissue/organ anatomy.

Bioprinting was successfully used to bioengineer functional left ventricles, using iPSC-derived CMs and type I collagen as the biomaterial (Figure 3A, Table 1) (11). One of the novel elements of this study was the use of a gelatin-based slurry to increase print fidelity. Traditional methods of bioprinting are based on extrusion of the bioink in air, a process that reduces print fidelity of soft biomaterials like gelatin, fibrin, alginate, and agarose. Rather than printing in air, printing directly into a support slurry provides support during the printing process, and once the print is complete, the support slurry is washed away through a temperature-dependent mechanism.

Using this process, a complete bioartificial left ventricle was bioprinted and shown to exhibit calcium transients with a calcium conduction velocity of $1.3 \mathrm{~cm} / \mathrm{s}$ and served to establish function of the bioprinted ventricles (11). However, the ventricles were printed as open structures, and as a result, it was not possible to measure LV pressure, a critical determinant of ventricle function and the most obvious next step for this technology.

\section{Biofabrication Technology 2: Pull-Spinning}

A recent study described the use of a novel fabrication method, known as pull-spinning, to bioengineer ventricles (Figure 3B, Table 1) (26). In this method, polycaprolactone (PCL) was mixed with gelatin, loaded into a syringe, ejected through a nozzle, and collected on a spinning mandrel to replicate the anatomical characteristics of the human left ventricle (26). The ventricle scaffold was populated with NVRM- or iPSCderived CMs. Calcium transients were used to assess function, pressures of $0.05 \mathrm{~mm} \mathrm{Hg}$ were noted, and pressure-volume relationships were demonstrated (26). These ventricles were then fitted with valves and cultured in a pulsatile flow bioreactor for mechanical conditioning (26). This was an outstanding study that clearly demonstrated the feasibility of bioengineering ventricles, including tri-leaflet valves and the use of bioreactors for mechanical loading of the bioengineered ventricles.

\section{Biofabrication Technology 3: Use of Balloon Catheters}

A very interesting approach is the use of Foley balloon catheters to provide support for a cell-laden mixture of type I collagen supplemented with matrigel and $\mathrm{CMs}$ derived from human embryonic stem cells (ESCs) (Figure 3C, Table 1) (27). The entire structure, balloon catheter, and CMs were housed in a custom chamber with $2 \%$ agarose being used as the sacrificial material (27). The collagen and CM mixture was allowed to gel in place for $24 \mathrm{~h}$ in the presence of the sacrificial material, which was then removed and supported the formation of a hollow chamber ventricle structure (27). Electrical stimulation was used during the culture period (27). Ventricles that were bioengineered using this method were shown to generate left ventricle (LV) pressures of $1.2 \mathrm{~mm} \mathrm{H}_{2} \mathrm{O}$ or $0.09 \mathrm{~mm} \mathrm{Hg}$ (27).

\section{Biofabrication Technology 4: Use of Custom Molds}

A series of four publications described a systematic and methodological process to bioengineer functional ventricles (Figure 3D, Table 1) (28-31). All studies were based on chitosan as the biomaterial and NVRMs were used as the cell source. The first study described the fabrication of an open ventricle mold, the second study described a novel 2-stage cellularization strategy, the third study described the use of bioreactors, and the fourth study included valves to complete the left ventricle model. These four studies are described in detail below.

Study 1: Development of an open ventricle-this study was focused on developing and validating the fabrication of ventricles and on material synthesis and characterization (30). Custom molds were machined to replicate the geometrical properties of human neonatal left ventricles, and chitosan was used as the biomaterial (30). A detailed material characterization was presented and included scanning 
electron microscopy, atomic force microscopy, and Fourier transform infrared for spectral analysis, all of which served to demonstrate the suitability of chitosan for ventricle bioengineering (30).

Study 2: 2-stage cellularization strategy-in previous studies, direct cell injection has been used to cellularize scaffolds, though this is known to result in low cell retention as a large number of cells are washed away (32). This remains a major challenge in the field of tissue engineering. This second study in this series addressed this problem and developed a novel 2-stage cellularization strategy to improve cell retention. Stage 1 consisted of direct injection of NVRMs within the ventricle scaffold. Subsequently, in stage 2, a highly contractile $3 \mathrm{D}$ cardiac patch was anchored on the outer surface of the cellularized ventricles. The contractile cardiac patch increased cell retention by providing a barrier function and also provided contractile support for the bioengineered ventricles (31).

Study 3: bioreactor conditioning-after developing the methodology to bioengineer ventricles and the development of a novel 2-stage cellularization strategy, the next step in the technology development was the fabrication of pulsatile flow bioreactors (28). Bioreactors were custom fabricated and were designed to mechanically load the bioengineered ventricles, designed to increase the contractile performance of the bioengineered ventricles. Culturing the ventricles in these custom bioreactors for $20 \mathrm{~h}$ resulted in a significant increase of pressure, from $0.2635 \pm 0.1087 \mathrm{~mm} \mathrm{Hg}$ to 3.1633 $\pm 0.3589 \mathrm{~mm} \mathrm{Hg}$ (28).

Study 4: left ventricles with valves-In the fourth and final study, the model of the neonatal left ventricle was completed by the incorporation of a valve, also fabricated using chitosan (29). This resulted in the formation of a complete left ventricle, similar in form and function to human left ventricles and a truly outstanding accomplishment in the field of ventricle tissue engineering.

\section{WHERE HAVE WE BEEN?}

Our approach to answering this question is to explore at different strategies for the key components of the ventricle fabrication process, namely, fabrication technology, biomaterial, cell source, bioreactors, and functional assessment; see Table 1. The goal is to critically evaluate the current state of the art and provide a directive moving forward.

\section{Fabrication Technology}

There have been four different methods to bioengineer ventricles $(11,26,27,29)$. Bioprinting relies upon a mechanical force to extrude bioink (11), pull-spinning relies upon a rotating mandrel to collect extruded fibers (26), use of balloon catheters relies upon an external support to bioengineer hollow ventricles (27), and custom molds cast the biomaterial in the form of a ventricle (29). All fabrication methods have proven successful in bioengineering functional ventricles. None has a clear advantage. A pre-requisite to the field of ventricle tissue engineering progressing is both refinement of existing fabrication methods and development of additional technology to support ventricle bioengineering.

\section{Biomaterials}

The most broad area of ventricle bioengineering, with many different biomaterials being used [chitosan (29), type I collagen $(11,27)$, and a mixture of PCL and gelatin (26)]. As the field progresses, additional biomaterials will need to be developed that more closely match the mechanical and biological properties of mammalian ventricles and this continues to be an area of active investigation $(18,33)$.

\section{Cell Sourcing}

The gold standard in the field is iPSC-derived CMs, as they provide an autologous source of contractile CMs. However, these cells are expensive to generate, limited in number, and functionally immature. NVRMs are abundant, inexpensive, and reproducible. An efficient interplay between NVRMs and iPSCderived CMs will be critical for the advancement of ventricle tissue engineering, with the former being used for model development and validation studies and the latter being used for translational studies.

\section{Bioreactor Technology}

The need for bioreactors in ventricle tissue engineering is well-established in the field, and recent publications have demonstrated the importance of electrical stimulation (27) and pulsatile fluid flow (28). However, customization by individual labs reduces comparison of results and efficient flow of information between individual researchers, a problem that can be solved by open-source sharing of bioreactor designs by independent Scientist in the field.

\section{WHERE DO WE NEED TO GO?}

While much progress has been made in the field of ventricle tissue engineering, a structured and methodological approach is needed moving forward. Here we provide guidance for the field of ventricle tissue engineering moving forward. Model development and optimization studies need to be conducted with NVRMs to achieve left ventricular pressures of $120 \mathrm{~mm} \mathrm{Hg}$ coupled with parallel studies using iPSC-derived CMs for patient-specific disease models, for biomarker development and development of new investigational strategies. CMs derived from iPSCs are known to be immature, and the ability to develop maturation paradigms is critical for the field of ventricle tissue engineering and tissue engineering as a whole. Controlled electromechanical regimes coupled with chemical conditioning using growth factors and cytokines are required to achieve this. New biomaterial formulations continue to be developed and optimized, and existing tissue fabrication methods continue to be refined and adopted for ventricle bioengineering (34). A critical hurdle that needs to be overcome is the development of patent vasculature that can support the viability of contracting CMs. This is critical to supporting the metabolic activity of contracting cells, and in the absence of engineered vasculature, tissue-engineered constructs are limited in thickness. 
Bioreactors need to be more consistent between labs to allow information exchange $(35,36)$, which in turn will accelerate development of ventricles for any given applications; sharing of software and code hardware components through opensource mechanisms will be required and will be a much-needed advancement in the field of ventricle tissue engineering.

Though challenges remain in the field, recent advances provide positive guidance and suggest that

\section{REFERENCES}

1. Virani SS, Alonso A, Benjamin EJ, Bittencourt MS, Callaway CW, Carson AP, et al. Heart disease and stroke statistics-2020 update: a report from the American heart association. Circulation. (2020) 141:e139-e596. doi: 10.1161/CIR.0000000000000757

2. Montero P, Flandes-Iparraguirre M, Musquiz S, Perez Araluce M, Plano D, Sanmartin C, et al. Cells, materials, and fabrication processes for cardiac tissue engineering. Front Bioeng Biotechnol. (2020) 8:955. doi: $10.3389 /$ fbioe. 2020.00955

3. Pomeroy JE, Helfer A, Bursac N. Biomaterializing the promise of cardiac tissue engineering. Biotechnol Adv. (2020) 42:107353. doi: 10.1016/j.biotechadv.2019.02.009

4. Vacanti JP, Morse MA, Saltzman WM, Domb AJ, Perez-Atayde A, Langer R. Selective cell transplantation using bioabsorbable artificial polymers as matrices. J Pediatr Surg. (1988) 23:3-9. doi: 10.1016/S0022-3468(88)80529-3

5. Hasan A, Saliba J, Pezeshgi Modarres H, Bakhaty A, Nasajpour A, Mofrad MRK, et al. Micro and nanotechnologies in heart valve tissue engineering. Biomaterials. (2016) 103:278-92. doi: 10.1016/j.biomaterials.2016.07.001

6. Chen SG, Ugwu F, Li WC, Caplice NM, Petcu E, Yip SP, et al. Vascular tissue engineering: advanced techniques and gene editing in stem cells for graft generation. Tissue Eng Part B Rev. (2020). doi: 10.1089/ten.teb.2019.0264

7. Markou M, Kouroupis D, Badounas F, Katsouras A, Kyrkou A, Fotsis T, et al. Tissue engineering using vascular organoids from human pluripotent stem cell derived mural cell phenotypes. Front Bioeng Biotechnol. (2020) 8:278. doi: $10.3389 /$ fbioe. 2020.00278

8. Yao T, Baker MB, Moroni L. Strategies to improve nanofibrous scaffolds for vascular tissue engineering. Nanomaterials. (2020) 10:887. doi: 10.3390/nano10050887

9. Dikici S, Claeyssens F, MacNeil S. Bioengineering vascular networks to study angiogenesis and vascularization of physiologically relevant tissue models in vitro. ACS Biomater Sci Eng. (2020) 6:3513-28. doi: 10.1021/acsbiomaterials.0c00191

10. Guy AA, Justin AW, Aguilar-Garza DM, Markaki AE. 3D printable vascular networks generated by accelerated constrained constructive optimization for tissue engineering. IEEE Trans Biomed Eng. (2020) 67:1650-63. doi: 10.1109/TBME.2019.2942313

11. Lee A, Hudson AR, Shiwarski DJ, Tashman JW, Hinton TJ, Yerneni S, et al. $3 \mathrm{D}$ bioprinting of collagen to rebuild components of the human heart. Science. (2019) 365:482-7. doi: 10.1126/science.aav9051

12. Noor N, Shapira A, Edri R, Gal I, Wertheim L, Dvir T. 3D printing of personalized thick and perfusable cardiac patches and hearts. Adv Sci. (2019) 6:1900344. doi: 10.1002/advs.201900344

13. Abbasgholizadeh R, Islas JF, Navran S, Potaman VN, Schwartz RJ, Birla RK. A highly conductive $3 \mathrm{D}$ cardiac patch fabricated using cardiac myocytes reprogrammed from human adipogenic mesenchymal stem cells. Cardiovasc Eng Technol. (2020) 11:205-18. doi: 10.1007/s13239-019-00451-0

14. Tao ZW, Mohamed M, Jacot JG, Birla RK. Bioengineering cardiac tissue constructs with adult rat cardiomyocytes. ASAIO J. (2018) 64:e105-e14. doi: 10.1097/MAT.0000000000000765

15. Tao ZW, Mohamed M, Hogan M, Gutierrez L, Birla RK. Optimizing a spontaneously contracting heart tissue patch with rat neonatal cardiac cells on fibrin gel. J Tissue Eng Regen Med. (2017) 11:153-63. doi: 10.1002/te rm.1895 the ability to bridge the functional gap between bioengineered and human ventricles is achievable in the near future.

\section{AUTHOR CONTRIBUTIONS}

The author confirms being the sole contributor of this work and has approved it for publication.

16. Tao ZW, Mohamed M, Hogan M, Salazar B, Patel NM, Birla RK. Establishing the framework for fabrication of a bioartificial heart. ASAIO J. (2015) 61:42936. doi: 10.1097/MAT.0000000000000233

17. Mohamed MA, Hogan MK, Patel NM, Tao ZW, Gutierrez L, Birla RK. Establishing the framework for tissue engineered heart pumps. Cardiovasc Eng Technol. (2015) 6:220-9. doi: 10.1007/s13239-015-0211-4

18. Vozzi F, Logrand F, Cabiati M, Cicione C, Boffito M, Carmagnola I, et al. Biomimetic engineering of the cardiac tissue through processing, functionalization, and biological characterization of polyester urethanes. Biomed Mater. (2018) 13:055006. doi: 10.1088/1748-605X/aaca5b

19. Birla RK, Williams SK. 3D bioprinting and its potential impact on cardiac failure treatment: an industry perspective. APL Bioeng. (2020) 4:010903. doi: $10.1063 / 1.5128371$

20. Zhang YS, Arneri A, Bersini S, Shin SR, Zhu K, Goli-Malekabadi Z, et al. Bioprinting 3D microfibrous scaffolds for engineering endothelialized myocardium and heart-on-a-chip. Biomaterials. (2016) 110:45-59. doi: 10.1016/j.biomaterials.2016.09.003

21. Maiullari F, Costantini M, Milan M, Pace V, Chirivi M, Maiullari S, et al. A multi-cellular 3D bioprinting approach for vascularized heart tissue engineering based on HUVECs and iPSC-derived cardiomyocytes. Sci Rep. (2018) 8:13532. doi: 10.1038/s41598-018-31848-x

22. Lee W, Hong Y, Dai G. 3D bioprinting of vascular conduits for pediatric congenital heart repairs. Transl Res. (2019) 211:35-45. doi: 10.1016/j.trsl.2019.03.007

23. Stower H. Bioprinting a human heart. Nat Med. (2019) 25:1330. doi: 10.1038/s41591-019-0585-1

24. Andriotis EG, Eleftheriadis GK, Karavasili C, Fatouros DG. Development of bio-active patches based on pectin for the treatment of ulcers and wounds using 3D-bioprinting technology. Pharmaceutics. (2020) 12:56. doi: 10.3390/pharmaceutics12010056

25. Roche CD, Brereton RJL, Ashton AW, Jackson C, Gentile C. Current challenges in three-dimensional bioprinting heart tissues for cardiac surgery. Eur J Cardiothorac Surg. (2020) 58:500-10. doi: 10.1093/ejcts/ezaa093

26. MacQueen LA, Sheehy SP, Chantre CO, Zimmerman JF, Pasqualini FS, Liu X, et al. A tissue-engineered scale model of the heart ventricle. Nat Biomed Eng. (2018) 2:930-41. doi: 10.1038/s41551-018-0271-5

27. Li RA, Keung W, Cashman TJ, Backeris PC, Johnson BV, Bardot ES, et al. Bioengineering an electro-mechanically functional miniature ventricular heart chamber from human pluripotent stem cells. Biomaterials. (2018) 163:116-27. doi: 10.1016/j.biomaterials.2018.02.024

28. Patel NM, Birla RK. Pulsatile flow conditioning of three-dimensional bioengineered cardiac ventricle. Biofabrication. (2016) 9:015003. doi: 10.1088/1758-5090/9/1/015003

29. Patel NM, Birla RK. The bioengineered cardiac left ventricle. ASAIO J. (2018) 64:56-62. doi: 10.1097/MAT.0000000000000642

30. Patel NM, Mohamed MA, Yazdi IK, Tasciotti E, Birla RK. The design and fabrication of a three-dimensional bioengineered open ventricle. J Biomed Mater Res B Appl Biomater. (2017) 105:2206-17. doi: 10.1002/jbm.b.33742

31. Patel NM, Yazdi IK, Tasciotti E, Birla RK. Optimizing cell seeding and retention in a three-dimensional bioengineered cardiac ventricle: the two-stage cellularization model. Biotechnol Bioeng. (2016) 113:2275-85. doi: 10.1002/bit.25992

32. Aslan A, Allahverdiyev AM, Bagirova M, Abamor ES. Problems in stem cell therapy for cardiac repair and tissue engineering approaches based on 
graphene and its derivatives. Curr Stem Cell Res Ther. (2018) 13:447-57. doi: 10.2174/1574888X13666180510110055

33. Pena B, Laughter M, Jett S, Rowland TJ, Taylor MRG, Mestroni L, et al. Injectable hydrogels for cardiac tissue engineering. Macromol Biosci. (2018) 18:e1800079. doi: 10.1002/mabi.201800079

34. Blan NR, Birla RK. Design and fabrication of heart muscle using scaffoldbased tissue engineering. J Biomed Mater Res A. (2008) 86:195-208. doi: $10.1002 /$ jbm.a. 31642

35. Birla RK, Huang YC, Dennis RG. Development of a novel bioreactor for the mechanical loading of tissue-engineered heart muscle. Tissue Eng. (2007) 13:2239-48. doi: 10.1089/ten.2006.0359

36. Paez-Mayorga J, Hernandez-Vargas G, Ruiz-Esparza GU, Iqbal HMN, Wang $\mathrm{X}$, Zhang YS, et al. Bioreactors for cardiac tissue engineering.
Adv Healthc Mater. (2018) 8:e1701504. doi: 10.1002/adhm.201 701504

Conflict of Interest: RB is CSO of a Biotech Company that worked on bioprinting human hearts.

Copyright (๑) 2020 Birla. This is an open-access article distributed under the terms of the Creative Commons Attribution License (CC BY). The use, distribution or reproduction in other forums is permitted, provided the original author(s) and the copyright owner(s) are credited and that the original publication in this journal is cited, in accordance with accepted academic practice. No use, distribution or reproduction is permitted which does not comply with these terms. 